\title{
Rural household livelihood strategies: Options and determinants in the case of Wolaita Zone, Southern Ethiopia
}

\author{
Yishak Gecho ${ }^{1, *}$, Gezahegn Ayele ${ }^{2}$, Tesfaye Lemma ${ }^{1}$, Dawit Alemu ${ }^{3}$ \\ ${ }^{1}$ Department of Rural Development and Agricultural Extension, Haramaya University, Ethiopia \\ ${ }^{2}$ Capacity Building Manager (USAID) to improve agriculture and food security, Addis Ababa, Ethiopia \\ ${ }^{3}$ Agricultural Economic Research -Extension Farmer's Linkage, Ethiopian Institute for Agricultural Research, Addis Ababa, Ethiopia
}

\section{Email address:}

yishakgecho@yahoo.com (Yishak G.), ayeleg@yahoo.com (Gezahegn A.), t.lemma41@yahoo.com (Tesfaye L.), dawit96@yahoo.com (Dawit A.)

\section{To cite this article:}

Yishak Gecho, Gezahegn Ayele, Tesfaye Lemma, Dawit Alemu. Rural Household Livelihood Strategies: Options and Determinants in the Case of Wolaita Zone, Southern Ethiopia. Social Sciences. Vol. 3, No. 3, 2014, pp. 92-104. doi: 10.11648/j.ss.20140303.15

\begin{abstract}
Due to sever land scarcity, high population pressure and recurrent drought, farm households in the study area widely engage in and pursue diverse activities as livelihood strategies. The carrying capacity of agriculture to attain food and livelihood security is extremely declining from time to time. Diversifying livelihood strategies at current time become a common phenomenon in the study area. The major objectives of this study are, therefore, to identify the existing livelihood strategies adopted by rural households and to assess factors that determine households' decision to choose alternative livelihood strategies. For the purpose of this study primary data were collected from randomly selected 300 households in four woredas (districts) of the zone. Descriptive statistics was applied to characterize the sample households' social, economic, demographic and institutional factors. The finding of the survey result indicates that rural households in the study area practice diversified livelihood strategies, in that large part of the respondents (57.7\%) combine agriculture with other activities (non/off-farm). Surprisingly, some farmers were pursuing non-farm and off-farm activities as the primary livelihood strategies rather than agriculture. Multinomial logit model applied to investigate factors influencing the households' choice of livelihood strategies. In this regard, a total of 19 explanatory variables were included in the empirical model of which 11 were significant. These variables include agro-ecology, sex, education, farm size, livestock ownership, participation in social leadership, annual cash income, fertilizer use, improved seed use, age, and training which were determining farmers' choice of livelihood strategies. The results of this study suggest that development interventions, policies and supportive services should be designed to suit the felt needs and circumstances of different groups of farmers.
\end{abstract}

Keywords: Livelihood Strategies, Rural Households, Ethiopia, Multinomial Logit Model

\section{Introduction}

Agriculture still remains the main stay of Ethiopian economy, which contributes $45 \%$ GDP, more than $80 \%$ of employment opportunities and over $90 \%$ of the foreign exchange earnings of the country [1]. It serves as the primary means of livelihoods. Though Ethiopia's economy has been growing at an average rate of $7 \%$ in recent years $[2,3]$ the increasing population growth in rural Ethiopia obliged households to cultivate and make their living on extremely small size of land. For instance, $29 \%$ of grain farmers in 2006/7 had cultivated a land less than 0.5 ha per household [4]. According to recent FDRE [5] evidence, nearly 55 percent of all smallholder farmers operate on one hectare or less. Due to the smaller farm size and low return from farming activities, majority of rural households are exposed to food insecurity and chronic poverty. Similarly, FAO [6] indicated that in Sub-Saharan Africa population growth is out stripping the current productive capacity of the land. The national survey conducted in 2003/4 by EEA indicated that $63 \%$ of surveyed households were food deficit in Ethiopia. This evidence is supported by FAO [7] in that about 61 percent people were undernourished in Ethiopia.

It is increasingly becoming clear that the agricultural sector alone cannot be relied upon as the core activity for rural households as a means of improving livelihood and reducing poverty. One phenomenon that is gaining 
prominence in the rural development literature is the promotion and support for non-farm diversification opportunities [8]. Non/off-farm economic activities include seasonal migration, off-farm to engage in wage employment, handicraft production, trading and processing of agricultural produce, provision of agricultural services etc. Such nonfarm activities provide a way of off-setting the diverse forms of risks and uncertainties (relating to climate, finance, markets etc) associated with agriculture and create a way of smoothing income over years and seasons $[9,10]$.

The rural economy of Ethiopia, similar to developing countries is traditionally viewed as agrarian economy in which farm households are exclusively engaged in farming with few non-farm activities. However, there is growing evidence that households across the developing world earn an increasing share of their income from non-farm sources. For example, Haggblade, Hazell and Reardon [11] reported that non-farm earnings account for 30 to 45 percent of rural household income across the developing world, and where available, evidence suggests that the non-farm share in rural income is increasing overtime. World Bank [12] also indicated that about 25 percent of rural households in Ethiopia earn some income from non-farm enterprises.

Similarly, outside agriculture the rural households in Wolaita zone generate income from non/off-farm wage, trading and remittance from migrants. Distant migration as a way to maximize income across seasons and cope with food shortage has been a long history. However, the majority (more than 50\%) of the population lives on subsistence margin with little or almost no land and livestock and dependent on marginal non-farm income sources (i.e., casual labor, petty trade). The very poor are often without working labor, with no assets (i.e., land, livestock) and dependent on income transfers [13]. The most recent evidence indicates that about 57 percent of households in the zone are possessing less than 0.25 hectare of land which could not help to attain adequately hand to mouth subsistence farming [14]. If there are no alternative means of livelihoods substituting this situation the newly born generation will face serious challenges than existing.

Moreover, the rural population in the Zone is frequently and increasingly vulnerable to droughts and famine. According to the study by Dessalegn [15], since the mid1980s, farmers in Wolaita have suffered hunger and food shortage almost continuously. The good years in the two decades have been very few. Since then, crisis interventions by government and NGOs have occurred almost every two years or so; and a number of farm households were highly dependent on food aid and other public support programs (ibid). The resilience of enset as 'famine crop' has diminished since the major droughts of the mid-1980s [ 13].This situation has reached peak stage and challenging many people at this time due to seasonal climate variation and uncontrolled population growth. Livestock holdings are on decline because of shortage of grazing areas and feed availability, drought and animal disease. With farm size and productivity declining, scarce non-farm income and depleting assets, the capacity of the rural population has thus diminished to cope with droughts and production failures.

Like the national economy of Ethiopia, households in study area are mainly dependent on small scale subsistence agriculture to derive their livelihoods. Nevertheless, the decline in carrying capacity of agriculture forces rural farm households to engage in diverse off/non-farm livelihood activities to maintain and improve their livelihood/wellbeing. Comprehending the driving factors of each livelihood strategy is crucial to improve the response mechanisms related to poverty, food security and livelihoods improvement in the study area. However, research work on household livelihood strategies and activities under a condition of resource scarcity in study area is limited. The factors that determine the selection of existing livelihood strategies are not well identified. Available livelihood strategies pursued by rural people in the study area are not assessed in detail. This study therefore aims to identify the existing livelihood strategies adopted by rural farm households; and assess factors that determine households' choice of available livelihood strategies in the zone.

\section{Methodology}

\subsection{Description of Study Area}

The study area, Wolaita Zone, is one of 13 Zones in southern Nation Nationalities and Peoples Regional State (SNNPRS) of Ethiopia. It is located at $390 \mathrm{~km}$ to southwest from the capital city of the country, Addis Ababa along the main road that passes through Shashamane to Arbaminch. Now, newly constructed Sodo-Hosana asphalted road reduced the distance to Addis Ababa, which is about $330 \mathrm{~km}$ away from the capital city of the country following main road that passes through Hosanna to Arbaminch. The Zone is roughly located between $6.4^{0}-7.1^{0} \mathrm{~N}$ and $37.4^{\circ}-38.2^{\circ} \mathrm{E}$, latitude and longitude respectively. It covers a total area of $4,511 \mathrm{~km} 2$ and is composed of 12 administrative weredas and 3 registered towns. According to Central Statistical Agency report of 2010, total number of population of the area is about $1,581,650$. Population density of the area is estimated at 385 per square kilometer [16]. The Zone is classified into three agro ecological zone, among them large proportion is Waina-Dega (mid-altitude) which is about $56 \%$ of the area; the rest $35 \%$ and $9 \%$ is described as Kola (low altitude), and Dega (high altitude) respectively. The estimated average annual rainfall is 801 to $1600 \mathrm{~mm}$. The rainfall in the Zone is characterized by bimodal distribution pattern and the main rainy season (Maher) is between Junes and continues up to end of September and Belg is from late February to late March/early April. The annual average temperature of the zone is $21.86^{\circ} \mathrm{C}$. The altitude of the zone ranges from 501 to 3000 meter above sea level [14]. 


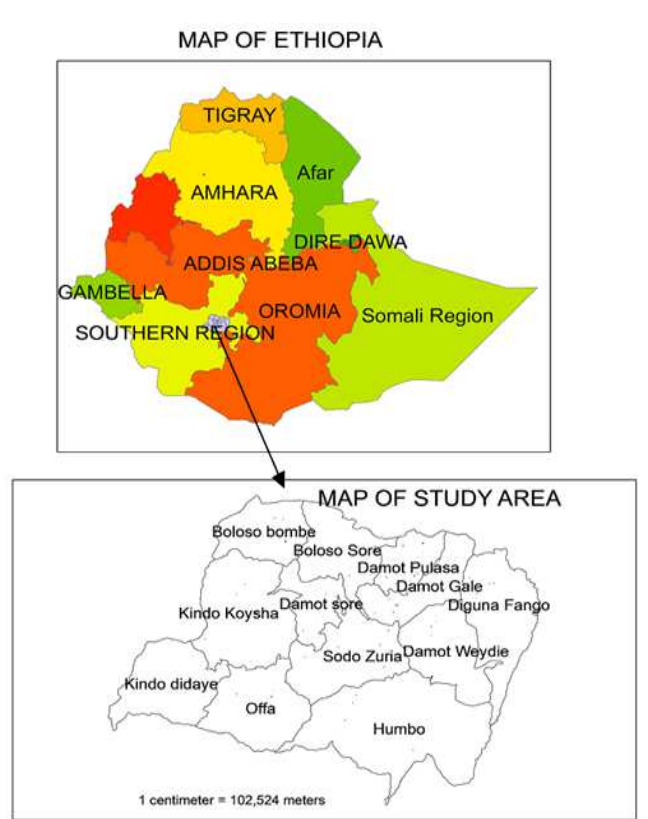

\subsection{Sampling Techniques}

In this study, multi-stage sampling procedure was employed to select sample households. In the first stage, out of the 12 woredas in the Zone, four woredas (Humbo, Damot Woyde, Sodo Zuria and Damot Gale) were selected purposively to capture different agro-ecological zones existing in the area which may determine household's livelihood activities. In the second stage, the kebeles in each woreda were listed based on their agro-ecological characteristics and grouped/stratified into three ecological zones highland, midland and low land. Based on this, 16 sample kebeles were selected by using simple random sampling techniques from each category of agro-ecological zone taking into account the number of kebeles in each Woreda. In the third stage, sampling frame (complete village household lists) was obtained from each kebele's administrative office. Then, wealth ranking exercise was conducted with help of participatory rural appraisal (PRA) tools in order to classify households under the different wealth categories. In the fourth stage, the probability proportional to sample size methods were applied to draw the sample household from each wealth category according to the number of household in different category. Finally, a total sample of 300 households was selected by using systematic random sampling techniques, of which 145, 105 and 50 were poor, medium (less poor) and better-off households respectively.

\subsection{Types and Methods of Data Collection}

To utilize and describe the various data sources triangulation were applied. Both primary and secondary data were used which are qualitative and quantitative in nature. Primary data was collected from sample households using structured interview schedules. Secondary data was obtained from different relevant secondary sources. In addition to this, focus group discussion, key informant interview and wealth ranking were conducted to supplement the research finding with qualitative information. Prior to actual survey, pre-test on non-sample respondents was conducted under supervision of the researcher and necessary modification was made on the basis of the results obtained. The data were collected in the month of April to May, 2013. One year was the recall time for the collected data.

\subsection{Methods of Data Analysis}

Two types of data analysis, namely descriptive statistics and econometric models were used to analyze the data collected from sample households. Quantitative categorical types of data were analyzed using percentage, frequency and chi-square test. While quantitative continuous types of variables were analyzed using one way ANOVA, minimum, maximum, mean and standard deviation. Interpretation and tabulation of data were done in order to analyze the qualitative data. After computing the descriptive statistics, multinomial logistic regression was used to identify determinants of household's choice of livelihood strategies where the dependent variable was found to be multi outcome. The data analysis was conducted using Statistical Package for Social Sciences (SPSS) version 16 and STATA 11.

\subsection{Multinomial Logit Model Specification}

When there is a dependent variable with more than two alternatives among which the decision maker has to choose (i.e. unordered qualitative or polytomous variables), the appropriate econometric model would be either multinomial logit or multinomial probit regression model. Regarding estimation, both of them estimate the effect of explanatory variables on dependent variable involving multiple choices with unordered response categories [17]. However, multinomial probit is rarely used in empirical studies due to estimation difficulty imposed by the need to solve multiple integration related to multivariate normal distribution [18]. Moreover, multinomial logit model is selected not only because of the computational ease but also multinomial logit analysis exhibits a superior ability to predict livelihood diversification and picking up the differences between the livelihoods strategies of rural households $[19,20]$. It is a simple extension of the binary choice model and is the most frequently used model for nominal outcomes that are often used when a dependent variable has more than two choices.

In this study therefore, a multinomial logit model specification was employed. This model makes it possible to analyze factors influencing households' choices of livelihood strategies in the context of multiple choices. Following Green [17], the multinomial logit model for a multiple choice problem is specified as follows: 


$$
p_{i j}=\frac{e^{x_{i} \beta_{j}}}{\sum_{j=1}^{j=4} e^{x_{i} \beta_{j}}}, j=1 \ldots 4
$$

Where $p_{i j}=$ the probability representing the $i^{\text {th }}$ respondent's chance of falling into category $j$ or (it is the probability of household $i$ 's choice of the livelihood strategies from category $j$ ), $x_{i}=$ is predictors of response probabilities; $e$ is the natural base of logarithms; and $\beta_{j}$ are the parameters to be estimated by maximum likelihood estimator (MLE). The estimated equations provide a set of probabilities for the $j+1$ choice for a decision maker with $x_{i}$ characteristics. For identification of the model, we need to conveniently normalize by assuming $\beta_{0}=0$ (Greene, 2000). Therefore, the probabilities are given by:

$$
\text { Prob. }\left(y_{i}=j / x_{i}\right)=p_{i j}=\frac{e^{x_{i} \beta_{j}}}{\sum_{j=2}^{J} e^{x_{i} \beta_{j}}}, \text { for } \mathrm{J}>1
$$

$$
\text { Prob. }\left(y_{i}=1 / x_{i}\right)=p_{i 1}=\frac{1}{1+\sum_{j=2}^{J} e^{x_{i} \beta_{j}}}
$$

The marginal effects $\left(\delta_{\mathrm{ij}}\right)$ of the characterstics on the probabilities are specified as

$$
\delta \mathrm{ij}=\frac{\partial p_{i j}}{\partial x_{i}}=p_{i j}\left[\beta_{j}-\sum_{j=0}^{J} P_{i j} \beta_{j}\right]=p_{i j}\left[\beta_{j}-\beta^{-}\right]
$$

\subsection{Descrption of Variables Used in Multinomial Logit Model and their Hypothesis}

Dependent variable: The dependent variable in this study was the selection of different livelihood strategies by farm households i.e. it was identified by categorizing the sample households into livelihood strategy groups based on their choice. Therefore, the polytomous dependent variable for multinomial logit was hypothesized to have the following values: $Y=1$, if the choice lies in farm alone; $Y=2$, if the choice lies in farm + non- farm; $Y=3$, if the choice lies in farm+ off- farm; $Y=4$, if the choice lies in farm + nonfarm + off-farm. Definitions and measurement of the

\begin{tabular}{|c|c|c|}
\hline Variables & Description and measurement & Expected Sign \\
\hline SEX & is a dummy variable taking value 1 if the household head is male, 0 otherwise & - \\
\hline AGE & Age of household head (year). & + \\
\hline EDUCTN & Formal education of household head (grades or number of years in school). & + \\
\hline FAMLSZ & Family size of household in Adult Equivalent (AE) & + \\
\hline DEPRAT & Dependent household members measured in number & + \\
\hline FARMSZ & Total farm size of household (hectare). & - \\
\hline TRLU & Total livestock owned by the farm household (TLU). & - \\
\hline FERTLZR & It is a dummy variable that takes value 1 if a household use fertilizer and 0 otherwise. & - \\
\hline IMSEED & It is a dummy variable takes 1 if a household use improved seed, 0 otherwise. & - \\
\hline EXTCNT & Number of time extension agent visited/advised farmer (number). & - \\
\hline TRAIN & Farmer attended formal agricultural training, dummy variable ( $=1$, if yes; $=0$, otherwise). & + \\
\hline CREDIT & Farmers access to credit, dummy variable $(=1$, if yes; $=0$, otherwise) & + \\
\hline MKTDISTN & Distance of the respondents' house from input and output market $(\mathrm{km})$ & - \\
\hline COOP & Households membership in cooperative organization, dummy variable $(=1$, if yes; $=0$, otherwise & + \\
\hline LEADER & $\begin{array}{l}\text { Households participation in local social leadership, dummy variable takes value of } 1 \text { if a household participated, } \\
0 \text { otherwise }\end{array}$ & + \\
\hline PSNP & It takes value 1 , if a household is beneficiary of safety net program, 0 if not involving in it. & + \\
\hline INCOM & Total annual cash income of households (Birr) & + \\
\hline AGROMID & $\begin{array}{l}\text { It is dummy variable, takes value } 1 \text { if a household living in mid-land, and } 0 \text { if residing in low land agro- } \\
\text { ecological zone. }\end{array}$ & - \\
\hline AGROHIGH & It is dummy variable, takes value 1 if a household living in high land, and 0 if residing in low land agro-ecology. & - \\
\hline
\end{tabular}
independent variables and their working hypothesis are described in Table 1.

Table 1. Definition and units of measurement of explanatory variables used in MLM

\section{Results and Discussion}

\subsection{Descriptive Statistics}

According to descriptive analysis, some variations were observed between four livelihood groups in terms of households' social, economic and institutional characteristics (Table 2). The four groups differ to some extent in their age, family size (AE), farm size, livestock ownership, frequency of extension contact, total annual cash income, using improved seed and fertilizer, access to credit, membership in cooperative and participation in local leadership. The study revealed that those farmers who were pursuing farming alone as their livelihood had relatively better farm size than the others. The mean value of farm size owned by those farmers relying on farm only for their 
livelihood strategies was 1.20 hectare, while it was less than a half of hectare for the rest three groups. Livestock ownership was another important household characteristic. Average livestock owned by the total sampled households was 3.65 TLU. Proportionally, those farmers depending on farm alone for their livelihood owned almost twice greater livestock than the rest categories. Variations were also observed in other socio-economic and institutional factors.

F-tests (ANOVA analysis) and chi-square tests were used to make sure presence or absence of difference $b / n$ the four groups of farmers, when appropriate. The mean values of continuous variables in all livelihood categories were compared using ANOVA analysis (F-test). According to Fvalues out of 9 continuous variables, the four categories were found to differ significantly in 6 of them (Table 2). The compared F-values indicated the mean differences for six variables, namely age, family size, farm size, number of tropical livestock units, frequency of extension contact and total annual cash income.

Table 2. Descriptive statistic for continuous explanatory variables

\begin{tabular}{lllllll}
\hline \multirow{2}{*}{ Variable } & \multicolumn{2}{l}{ Livelihood strategies of the household } & & & \\
\cline { 2 - 6 } & Farm only & Farm and non-farm & Farm and off-farm & Farm, non-farm and off-farm & Total & F-value \\
\cline { 2 - 6 } & Mean & Mean & Mean & Mean & 43.31 & $5.363^{* * *}$ \\
\hline Age & 45.9 & 42.15 & 39.35 & 41.09 & 4.16 & 1.255 \\
Education & 3.98 & 4.66 & 3.42 & 4.00 & 5.29 & $7.987^{* * *}$ \\
Family size (AE) & 5.83 & 5.06 & 4.37 & 5.02 & 1.05 & 1.433 \\
Dependency ratio & .94 & 1.12 & 1.21 & 1.13 & .76 & $22.916^{* * *}$ \\
Farm size & 1.20 & .51 & .33 & .35 & 3.65 & $39.551^{* * *}$ \\
TLU & 5.47 & 2.82 & 1.32 & 1.67 & 9.88 & $19.767^{* * *}$ \\
Extension contact & 13.64 & 8.97 & 3.50 & 4.32 & 7.56 & 1.926 \\
Market distance & 8.23 & 6.86 & 7.62 & 3.09 & 5590.5 & $14.424^{* * *}$ \\
Annual cash income & 7384.53 & 5050.48 & 2581.42 & & 3430.04 & \\
\hline
\end{tabular}

Source: survey result, 2013. ${ }^{* * *}$, stands for significant at $1 \%$

On the other hand, a chi-square test was used to examine the existence of statistically significance difference $b / n$ the discrete variables of four categories. Accordingly, discrete variables were considered and the four categories were found to be different in terms of 9 of the 10 discrete variables (Table 3). More specifically, the chi-square test reveals that access to credit, participation in cooperative membership, using improved seed, using chemical fertilizer, involvement in local leadership, receiving safety net aid, participation training, receiving remittance and agroecology were statistically significant at less than 5\% probability level.

Table 3. Descriptive analytical results for discrete explanatory variables

\begin{tabular}{|c|c|c|c|c|c|c|c|}
\hline \multirow[b]{2}{*}{ Variables } & \multirow[b]{2}{*}{ Response } & \multicolumn{5}{|c|}{ Livelihood strategies of the households (\%) } & \multirow[b]{2}{*}{$\chi^{2}$} \\
\hline & & Farm only & $\begin{array}{l}\text { Farm and non- } \\
\text { farm }\end{array}$ & $\begin{array}{l}\text { Farm and off- } \\
\text { farm }\end{array}$ & $\begin{array}{l}\text { Farm, non-farm } \\
\text { and off-farm }\end{array}$ & Total & \\
\hline \multirow[t]{2}{*}{ Sex } & Male & 81.9 & 82 & 87.5 & 86.4 & 83 & \multirow{2}{*}{.943} \\
\hline & Female & 18.1 & 18 & 12.5 & 13.6 & 17 & \\
\hline \multirow[t]{3}{*}{ Agro-ecology } & Kola & 36.2 & 12.6 & 30 & 22.7 & 25.7 & \multirow[t]{3}{*}{$26.824 * * *$} \\
\hline & $\mathrm{W} /$ dega & 54.3 & 59.5 & 60 & 59.1 & 57.3 & \\
\hline & Dega & 9.5 & 27.9 & 10 & 18.2 & 17 & \\
\hline \multirow[t]{2}{*}{ Fertilizer use } & Yes & 81.9 & 64.9 & 27.5 & 40.9 & 65.3 & \multirow[t]{2}{*}{$46.455 * * *$} \\
\hline & No & 18.1 & 35.1 & 72.5 & 59.1 & 34.7 & \\
\hline \multirow[t]{2}{*}{ Improved seed use } & Yes & 62.2 & 41.4 & 7.5 & 13.6 & 43.7 & \multirow[t]{2}{*}{$47.301 * * *$} \\
\hline & No & 37.8 & 58.6 & 92.5 & 86.4 & 56.3 & \\
\hline \multirow[t]{2}{*}{ Credit } & Yes & 28.3 & 38.7 & 27.5 & 45.5 & 33.3 & \multirow[t]{2}{*}{$4.948 * * *$} \\
\hline & No & 71.7 & 61.3 & 72.5 & 54.5 & 66.7 & \\
\hline \multirow[t]{2}{*}{ Membership } & Yes & 50.4 & 34.2 & 20 & 22.7 & 38.3 & \multirow[t]{2}{*}{$16.557 * * *$} \\
\hline & No & 49.6 & 65.8 & 80 & 77.3 & 61.7 & \\
\hline \multirow[t]{2}{*}{ Leadership } & Yes & 39.4 & 20.7 & 7.5 & 13.6 & 26.3 & \multirow[t]{2}{*}{$22.071 * * *$} \\
\hline & No & 60.6 & 79.3 & 92.5 & 86.4 & 73.7 & \\
\hline \multirow[t]{2}{*}{ Safety net aid } & Yes & 14.2 & 17.1 & 27.5 & 36.4 & 18.7 & \multirow[t]{2}{*}{$8.459 * *$} \\
\hline & No & 85.8 & 82.9 & 72.5 & 63.6 & 81.3 & \\
\hline \multirow[t]{2}{*}{ Training } & Yes & 69.3 & 53.2 & 17.5 & 13.6 & 52.3 & \multirow[t]{2}{*}{$47.33 * * *$} \\
\hline & No & 30.7 & 46.8 & 82.5 & 86.4 & 47.7 & \\
\hline
\end{tabular}

Source: survey result, 2013 . Note: $* * * \& * *$ represent significant at $1 \%$ and $5 \%$. 


\subsubsection{Household Livelihood Strategies}

Even if, agricultural land is declining from time to time, a significant part of the sample respondents still engaged in farming activities. As observed from the survey result about $42.3 \%$ of the total sample house households depend solely on agriculture (crop and animal production) for their livelihood strategies (Table 4). The remaining, large parts of the respondents $(57.7 \%)$ combine agriculture with other activities like non-farm and off-farm. The non-farm and off-farm activities help farmers to fill income and food gap that agriculture unable to do. In this regard, about $37 \%$ of the total sample households derived their livelihood from farm and non-farm activities (Table 4). The chi-square test shows the significant difference $b / n$ the three wealth groups regarding to the livelihood strategy choice at $1 \%$ probability level. This difference in livelihood strategies choice implies the existence of significant barriers in selection of the most remunerative livelihood strategy.

To compare the three wealth categories, more proportion
(84\%) of better-off households engaged solely on farming, while only $23.4 \%$ and about $48.6 \%$ of poor and medium households respectively pursue the same activities. Nonfarm activities play a crucial role in livelihood of the poor and medium households, which accounted about $39.3 \%$ of poor and $43.8 \%$ of medium households. Only $16 \%$ of better-off households derive their livelihood from farm plus non-farm activities. As the survey data indicates combing farm with off-farm activities is a main livelihood strategy of poor households (Table 4). The finding of this study depicts that large number of poor households engaged in non-farm and off-farm activities in addition to agriculture. Ghosh and Bharadwaj [21] also confirm this truth in that non-agricultural employment (non/off-farm activities) arises from the survival strategies of rural households unable to obtain employment or self-employment in agriculture. According to them, it is a last resort rather than an attractive alternative livelihood.

Table 4. Distribution of sampled household by livelihood strategies and wealth category

\begin{tabular}{|c|c|c|c|c|c|c|c|c|}
\hline \multirow{3}{*}{ Livelihood strategies } & \multicolumn{8}{|c|}{ Households' Wealth category } \\
\hline & \multicolumn{2}{|c|}{ Poor $(N=145)$} & \multicolumn{2}{|c|}{ Medium(N=105) } & \multicolumn{2}{|c|}{ Better-off $(\mathrm{N}=\mathbf{5 0})$} & \multicolumn{2}{|c|}{ Total $(\mathrm{N}=\mathbf{3 0 0})$} \\
\hline & $\mathbf{n}$ & $\%$ & $\mathbf{N}$ & $\%$ & $\mathbf{n}$ & $\%$ & $\mathbf{n}$ & $\%$ \\
\hline Farm alone & 34 & 23.4 & 51 & 48.6 & 42 & 84 & 127 & 42.3 \\
\hline Farm + non-farm & 57 & 39.3 & 46 & 43.8 & 8 & 10 & 111 & 37 \\
\hline Farm + off-farm & 36 & 24.8 & 4 & 3.8 & 0 & 00 & 40 & 13.3 \\
\hline Farm + non-farm + off-farm & 18 & 12.4 & 4 & 3.8 & 0 & 00 & 22 & 7.3 \\
\hline$\chi^{2}$ & & & & & & & 79.8 & \\
\hline P-value & & & & & & & .000 & \\
\hline
\end{tabular}

Source: survey result, 2013

\subsubsection{Income Composition of the Livelihood Activities}

As the finding of the study indicates, the major income sources for the sample households were crop sale, livestock and livestock product sale, petty trade/small business, causal wage, fire wood selling, rent of pack animals, and remittance. Among these, the most important source of income for all households by its share was found to be crop $(39.3 \%)$, livestock $(38.8 \%)$ and petty trade $(8 \%)$. The survey data also indicated that within groups of households where each household has the same economic opportunities; there is a large variation in both the size of income and in the relative importance of different sources of income. The study showed that farming activities dominantly pursued by all the three wealth categories with increasing share by the medium and better off households (Table 5).

Table 5 shows the contribution of each livelihood activities in income of the three wealth groups. Accordingly, the income composition of the poor from increasing order showed that livestock income (30.2\%), crop income (21.7), wage income from local, urban and other regions (17.9\%), petty trade $(13.8 \%)$, handcrafts $(10.3 \%)$, weaving $(2.4 \%)$.
The implication is that nearly half of cash income for poor households generated from non-farm and off-farm activities. Contrary to this, the income of the better off households' is composed of crop $(50.1 \%)$, livestock $(43.6 \%)$, remittance $(4.2 \%)$ and petty trade $(2.1 \%)$. This implies that the betteroff households' income is mainly from crop and livestock. Like the better-off households, on-farming (crop and animal production) activities share high percentage of medium households' income source. The possible justification for the medium and better off households' high share of on-farming income is that endowment of better productive resources. The reverse is true for poor group, which lacks adequate productive resources to generate livelihood outcomes. Berry [22] strengthen this fact in that poor farmers who increasingly engage in off-farm activities may rather be doing so as a long-term adaptation to stress, shocks and poverty - these farmers are trying simply to survive in a poorer, riskier world, rather than to improve livelihoods and invest in production.

Considering the income share of three main livelihood activities, the high share is taken by agriculture which accounts about $78.1 \%$, while non farm and off-farm part 
only about $16.5 \%$ and $5.4 \%$ respectively. The combined share of non-agricultural activities (non/off-farm) in the income of sample household was accounted about $22 \%$. The result approximates that the national level, in which the share of non-agricultural sector accounts for $25 \%$ [23]. This finding suggest that off-farm activities are survival mechanisms pursued mainly by the poor and medium groups but not viewed as an opportunity that farmers engage in as a choice, that means it is a pushing factor in absence of alternative livelihood activities. Comparing to the better-off households, non-farm activities is also the major choice of the poor and medium households (Table 5). Thus, off- farming activities seem more of a coping mechanism for the rural population than a way to accumulate wealth and reduce poverty. The poor tend to concentrate on off-farm activities with low entry constraints. This result leads to the understanding of the challenges which prevent the poor and less poor from engaging in livestock production and more remunerative non farm activities.

Table 5. Proportion of cash income composition generated from different livelihood activities

\begin{tabular}{lllll}
\hline \multirow{2}{*}{ Cash income composition } & \multicolumn{2}{l}{ Wealth category of $\mathbf{H H}(\mathbf{\%})$} & Total (N=300) \\
\cline { 2 - 4 } & Poor $(\mathbf{N}=\mathbf{1 4 5})$ & Medium(N=105) & Better-off (N=50) & 78.1 \\
\hline On-farm & 52 & 78.1 & 93.6 & 39.3 \\
Crop & 21.7 & 39 & 50.1 & 38.8 \\
Livestock and their product & 30.2 & 39.1 & 43.6 & 16.5 \\
Non-farm & 29.6 & 18.9 & 6.4 & 8 \\
Petty trade & 13.8 & 10.4 & 2.1 & 3.7 \\
Handcrafts & 10.3 & 3.4 & 00 & 0.8 \\
Weaving/spinning & 2.4 & 0.7 & 00 & 3.1 \\
Remittance & 1.5 & 2.8 & 4.2 & 0.9 \\
Local drink sale & 1.5 & 1.4 & 00 & 0.11 \\
Rent pack animal & 0.2 & 0.2 & 00 & 5.4 \\
Off-farm & 18.4 & 3 & 00 & 2.7 \\
Daily labor in local area & 9.5 & 1.2 & 00 & 1.5 \\
Daily labor near unban & 5.7 & 0.5 & 00 & 1.1 \\
Wage labor in other area & 2.7 & 1.2 & 00 & 0.2 \\
Fire wood/grass sale & 0.6 & 0.1 & 00 & 1675908.5 \\
Total sum of cash income & 392075.5 & 627087 & 656746 & 5590.5 \\
Mean & 2702.4 & 5990.4 & 13126.3 & \\
\hline
\end{tabular}

Source: survey result, 2013

\subsection{The Model Result}

Based on theoretical background and review of literature on related studies, multinomial logit model was employed for this study to estimate the effect of hypothesized explanatory variables on farmers' choice of livelihood strategies. The dependent variable is the category of farmers on adoption of livelihood strategies, taking a value of 1 if a farm household is pursuing farming only $\left(n_{1}=121\right)$, a value of 2 if selecting farming plus non-farming $\left(\mathrm{n}_{2}=111\right)$, a value of 3 if adopting farm with off-farm activities $\left(n_{3}=60\right)$ and a value of 4 if choice is farm plus non-farm and offfarm $\left(\mathrm{n}_{4}=22\right)$.

The variance inflation factor (VIF) and contingency coefficients were used to test the degree of multicollinearity and association among explanatory variables, respectively. Moreover, the model was run and tested for the validity of the independence of the irrelevant alternatives (IIA) assumptions by using Hausman test for IIA. The test failed to reject the null hypothesis of independence of the livelihood strategy options, suggesting that the multinomial logit (MNL) specification is appropriate to model households' livelihood strategy choice.

The maximum likelihood method was employed to estimate the parameter estimation of the multinomial logit model and statistically significant variables were identified in order to measure their relative importance on the farmers' decision to choose livelihood strategies. The STATA version 11 was used to generate the parameter estimates. The results of the maximum likelihood estimates are presented in the Tables 6 . The value of Pearson chi-square indicated the goodness of fit for the fitted model. The likelihood test ratio statistics indicated by the chi-square statistics is highly significant (sign. $=0.0000$ ) suggesting strong explanatory power of the model.

The parameter estimates of the multinomial logit model give only the direction of the effect of explanatory variables on the dependent variable, but the estimates neither stand for the actual size of change nor the probabilities [18]. However, the marginal effect measures the expected change in the probability of a given choice that has been made in relation to the unit change in the explanatory variable [17]. 
Table 6. Multinomial logit model results of households' choice of livelihood strategies

\begin{tabular}{|c|c|c|c|c|c|c|c|c|c|}
\hline \multirow{3}{*}{ Variable } & \multicolumn{9}{|c|}{ Households' livelihood strategies } \\
\hline & \multicolumn{3}{|c|}{ Farm +non-farm } & \multicolumn{3}{|c|}{ Farm +off-farm } & \multicolumn{3}{|c|}{ Farm+ non-farm + off-farm } \\
\hline & Coef. & P-value & $\begin{array}{l}\text { Marginal } \\
\text { effect }\end{array}$ & Coef. & P-value & $\begin{array}{l}\text { Marginal } \\
\text { effect }\end{array}$ & Coef. & P-value & $\begin{array}{l}\text { Marginal } \\
\text { effect }\end{array}$ \\
\hline AGROMID & .6274 & 0.176 & .1482 & -.6318 & 0.315 & -.0240 & -.6796 & 0.367 & -.0194 \\
\hline AGROHIGH & 2.9973 & $0.000 * * *$ & .6068 & .1988 & 0.861 & -.0346 & 1.028 & 0.384 & -.0179 \\
\hline SEX & -.3256 & 0.547 & -.0475 & -1.943 & $0.010 * * *$ & -.0404 & -1.325 & 0.135 & -.0226 \\
\hline AGE & .0379 & $0.087 *$ & .0089 & .02001 & 0.546 & .00004 & .0307 & 0.424 & .00025 \\
\hline EDUCT & .2551 & $0.000 * * *$ & .0586 & .2003 & $0.040 * *$ & .0017 & .2706 & $0.013 * *$ & .00294 \\
\hline FAMSZ & -.1751 & 0.110 & -.0405 & -.2653 & 0.140 & -.0042 & -.0146 & 0.941 & .0015 \\
\hline DEPRTO & -.0796 & 0.716 & -.0135 & -.2351 & 0.439 & -.0044 & -.3963 & 0.292 & -.00709 \\
\hline FARMSZ & -1.6520 & $0.010 * * *$ & -.3597 & -2.347 & $0.069^{*}$ & -.0347 & -2.683 & $0.092 *$ & -.03723 \\
\hline TRLU & -.4922 & $0.000 * * *$ & -.10152 & -1.158 & $0.000 * * *$ & -.0208 & -.8766 & $0.002 * * *$ & -.0124 \\
\hline FERTLZR & -.4064 & 0.420 & -.08349 & -1.247 & $0.069 *$ & -.0239 & -.4276 & 0.573 & -.00417 \\
\hline IMSEED & .1419 & 0.772 & .06332 & -1.636 & $0.079 *$ & -.0384 & -1.125 & 0.221 & -.02311 \\
\hline EXTNCNT & .0016 & 0.955 & .000012 & .0408 & 0.499 & .00091 & -.0034 & 0.957 & -.00011 \\
\hline TRAIN & -.1907 & 0.698 & -.02013 & -.7898 & 0.278 & -.0151 & -1.999 & $0.033^{* *}$ & -.0379 \\
\hline CREDIT & .1418 & 0.736 & .0206 & .3455 & 0.583 & .0058 & 1.161 & 0.101 & .0218 \\
\hline MKTDST & -.0248 & 0.558 & -.0047 & -.0782 & 0.184 & -.00149 & -.0627 & 0.377 & -.00098 \\
\hline $\mathrm{COOP}$ & -.2263 & 0.602 & -.0557 & .3477 & 0.635 & .01060 & -.4466 & 0.588 & -.00701 \\
\hline LEADER & -1.148 & $0.017^{* *}$ & -.2718 & -.6025 & 0.510 & -.00113 & -.7219 & 0.452 & -.00343 \\
\hline PSNP & -.2941 & 0.544 & -.0685 & -.6050 & 0.335 & -.0108 & .2193 & 0.753 & .00744 \\
\hline INCOM & .7515 & $0.013^{* *}$ & .1721 & .4660 & 0.265 & .0021 & 1.006 & $0.044 * *$ & .01293 \\
\hline CONSTA & -4.3802 & 0.111 & & 4.098 & 0.318 & & -5.551 & 0.252 & \\
\hline No. of obs. & & & & 300 & & & & & \\
\hline Log likelihood & & & & -231.539 & & & & & \\
\hline LR chi2(57) & & & & 252.13 & & & & & \\
\hline Prob $>$ chi2 & & & & $0.0000 * * *$ & & & & & \\
\hline Pseudo R2 & & & & 0.3525 & & & & & \\
\hline
\end{tabular}

Source: computed from own survey data, $2013 . * * * * *$, and $*$ stand for significant at $1 \%, 5 \%$ and $10 \%$. Standard errors and z-ratio are not reported here because of space constraints.

The result indicates that among 19 hypothesized explanatory variables seven, six and five variables were found to significantly influence choice of farm + non-farm, farm + off-farm and farm + non-farm and off-farm, respectively.

The multinomial logit model result indicates that agroecology (AGROEC), sex (SEX), education level of household (EDUC), farm size (FARSZ), livestock ownership (TRLU), participation in social leadership (LEADER), annual cash income (INCOM), fertilizer use (FRTLIZR), improved seed use (IMSEED), age (AGE), and training (TRAIN) were determining farmers choice of livelihood strategies (Table 6). However, the magnitude effect of some significant variables is not similar for the three livelihood strategies. Some may be highly significant to affect the choice of a strategy and may be insignificant for the other. Therefore, multinomial logit analysis results indicate selection of each type of livelihood strategy is affected by different factors and at different levels of significance by the same factor (Table 6). It has to be noted that the multinomial logit estimates are reported for three of the four categories of livelihood strategies choice. The first alternative (i.e. selecting farming only) was used as a benchmark alternative against which the choice of the other three alternatives was seen. The plausible implication and marginal effects of the significant explanatory variables on the choice of households' livelihood strategies are presented as follows:

Sex (SEX): It was found that sex had negatively and significantly affected the probability of diversifying the livelihood into off-farm activities at less than $1 \%$ probability level. This result implies that the households headed by female are less likely to participate in off-farm activities. The possible reason is households headed by female have more responsibilities in home management. Opposite to this, male household heads have more tendency of engaging in different activities and then this improves their income. As observed in study area there is traditional culture lead gender disparity which creates female-headed households to have less chance to participate in off-farm activities. Women mobility to urban area in search of offfarm activities is not culturally accepted and most of the societies perceive it in a negative angle. Other things keep constant, the likelihood of a household diversifying into off-farm activities decrease by $4 \%$ when household head become female. This result agrees with the prior finding by Ellis [24] and Adugna [25].

Age (AGE): The model result also indicated that the age 
of household head influenced positively and significantly the choice of farm + non-farm activities at less than $10 \%$ probability level. This study indicates that those farmers with old age are more likely diversify the livelihood strategies into non-farm activities. This result opposes the prior expectation, in that older household heads participate less in non-farm activities and at old age farm experience increases with age, consequently, this person have more prospects to maintain jobs in on-farm than non-farm. The probable justification for positive association is that as age increases farmers have more chance to have more children, this in turn help to have available labor to engage in diverse activities. The second reason, the increment in the number of children may result in more family members and this can create more demand for basic necessities. This situation, therefore, may force a household to engage in diversified livelihood strategies in order to meet basic needs of the family. From the model result, other variables being kept constant, the probability of a household choice of farm and off-farm activities is increased by $1 \%$ with a unit change in age. Similarly, Dilruba and Roy [26] and Ellis [24] shown that household-head age is the main driving force towards livelihood diversification.

Livestock ownership (TRLU): The ownership of livestock in TLU negatively and significantly affected the diversification of livelihood into non-farm, off-farm and combining non-farm and off-farm activities equally at less than $1 \%$ probability levels. This result suggests that a household having larger size of livestock are less likely to diversify the livelihood strategies into non-farm and/or offfarm activities compared to those who own small number of TLUs. In the study area, majority of farmers depend on livestock production for their farm income. The negative association between livelihood diversification and number of TLU indicates that herd size creates better opportunity to earn more income from livestock production. The income generated from livestock helps farmers to fulfill family requirement including food. Here, households who can get the required amount of food from livestock may not engage in another income generating activities unless their objective is to increase their asset holding. On the other hand, households with less number of livestock try to diversify their income portfolio by participating in non-farm and offfarm activities and this accelerates the rate of diversification. According to the study, keeping other variables constant, the likelihood of diversifying the livelihoods into farm + nonfarm and farm + off-farm activities decrease by $10.2 \%$, and $2.1 \%, 1.2 \%$ respectively, for those farmers with more TLU. Similarly, the probability of household's choice of combining non-farm and off-farm activities drops by $1.2 \%$ for increasing one additional unit in TLU. Different studies support this idea, for instance [27, 25).

Farm size (FARMSZ): It was found that farm size had negatively and significantly influenced the probability of livelihood diversification into farm + non-farm, farm + offfarm and farm + non-farm \& off-farm activities at less than $1 \%, 5 \%$ and $10 \%$ probability level respectively. This result implies that farmers with large farm size are less likely to diversify the livelihood strategies into non-farm and/or offfarm than those farmers who have small land size. Large farm size helps farmers to cultivate and produce more, which in turn increases farm income and improves livelihood of a household. On the other hand, declining land sizes under population pressure may encourage rural households to diversify their sources of income. That means, farmers having more land size relay on crop production than to go for non farm and off-farm in order to satisfy basic needs. The chance of livelihood diversification into non-farm, off-farm and combing non-farm \& off-farm activities decreases by $36 \% 3.5 \%$ and $3.7 \%$, respectively, for those farmers with large farm size in hectare. In other word, a unit increment in farm size results in decreasing $36 \%, 3.5 \%$ and $3.7 \%$ of household's livelihood strategies choice of farm + non-farm, farm + off-farm and farm + non-farm and off-farm activities, respectively. Similar study by Tesfaye [28] and Mujib et al. [29] revealed that insufficient arable land sizes are positively and significantly associated with participation of rural households in offfarm and non-farm activities.

Education (EDUCT): As the model result indicates, the variable education had positively and significantly influenced the household choices of farm + non-farm, farm + off-farm and farm + non-farm \& off-farm activities at less than $1 \%, 5 \%$, and $5 \%$ probability level respectively. This finding indicates that those farmers with high educational level are more likely diversify livelihood strategies into non-farming and/or off-farming activities than those do not. This is due to most probably educated person gain better skill, experience, knowledge and this again help them to engage in diversified livelihood strategies. Literate individuals are very ambitious to get information and use it. And it also determines the capability of finding a job. From the model result, the marginal effect reveals the likelihood of a household diversifying into nonfarm, off-farm and combination of non-farm and off-farm activities increase by $5.9 \%, 0.2 \%$ and $0.3 \%$, respectively, for those farmers with more level of education. In other words, adding one grade education can increase the chance of choosing non-farm and off-farm activities by aforementioned percent. Various authors [26, 30, and 31] in their research found education as an essential in increasing off/non-farm earnings and time allocation of rural families and to diversify the rural economy away from agriculture.

Agro-ecology (AGROEC): this variable was found to be positively and significantly influenced diversification of the livelihood strategies into farm plus non-farm at less than $1 \%$ probability level. This result demonstrates that the incidence/magnitude of diversifying the livelihood into farming with non-farming increases as we go from low land to high land. Declining of cultivated and grazing land, as the result of high population pressure in high land area, forces people to engage in alternative livelihood strategies like non-farm activities. Beside the negative drive, in high land there is also positive situation which creates good 
opportunities to engage in non-farming activities, especially availability of bamboo tree in the area helps farmers to engage in handcrafts. Farmers use bamboo tree as a main sources of income by making different furniture, fencing, and house construction and other home equipments. Producing cash crops like teff, coffee, and maize are limited in high land area and this in turn limit income sources. So, farmers diversify livelihood into nonfarming activities in order to fill this income gap. Opposite to this, in low land area population is sparsely distributed and land holding is relatively better than the other. This available land holding in low land allow farmers to produce crops and rare various types of livestock so that they stick mostly with farming. Thus, the probability of diversifying livelihood into farming with non-farming activity increases by $60.1 \%$ for those farmers who are living highland area. This result is inline with the prior study by Dilruba and Roy [26] in that agro-climatic condition is main driving force towards livelihood diversification.

Total annual cash income (INCOM): As expected, this variable was found to have positive and significant influence of livelihood diversification into non-farm and combination of non-farm and off-farm activities equally at less than 5\% probability level. This result implies that households having large cash income are more likely to diversify the livelihood strategies into non-farm and/or offfarm activities. On other word, this result shows that those farmers with low income are less likely to diversify livelihood strategies into non-farm and/or off-farm activities than those who have high income. The possible reason is that those farmers who have adequate income sources can overcome financial constraints to engage alternative livelihood strategies. Hence, higher income can encourage them to invest in other income generating activities especially non-farm activities. From the model result, other things being constant, the marginal effect reveals that the probability of a household diversifying into non-farm and combined non-farm and off-farm activities increased by $17.2 \%$ and $1.3 \%$, respectively, for those farmers with more level of income. Babatunde, Olagunju and Fakayode [30], Isaac [32] and Woinishet [33] show that the significant determinants of income on livelihood diversification into non-farm and/or off-farm activities.

Training (TRAIN): The model result indicated that agricultural training had negative and significant influence on livelihood strategies choice of farm plus non-farm and off-farm activities at less than 5 percent probability level. This implies that households' participation in agricultural training most likely decreases the likelihood of livelihood diversification into combing non-farm with off-farm activities. The probable reason is that the training enhances agricultural production skills, knowledge and experiences of farmers. This situation helps farmers to get better production, and then this most likely leads to obtain more income to fulfill their family requirements. According to the study, those households who are pursuing any livelihood strategies in combination with off-farming are almost poor. Hence, this households most probably conduct this activity not accumulate wealth, but due to the lack of opportunities to choice the better options. The finding of the model result also depicts that, other things being constant, the chance of diversifying the livelihood into offfarm and non-farm activities drop by $3.8 \%$ as the farmers involve in agricultural training. Opposite to this, study conducted by Dilruba and Roy [26] indicates the positive association of training and livelihood diversification.

Fertilizer use (FERTLZR): This variable has negative and significant influence on the household decision of selecting diversified livelihood strategies into farm + offfarm activities at less than $10 \%$ significant level. This means that those farmers who have access to fertilizer use are less likely adopt farming with off-farming activities as a livelihood strategy than those who have no access. The reverse is true for those households who haven't used fertilizer in their farm. The possible justification is that using fertilizer most likely increase the production and productivity of crops, and this can help farmer to get access to more food and generate more income so that they satisfy their family requirements. Thus, households may not wonder searching 'demand push' livelihood strategies like off-farm activities. The result indicates that, other factor kept constant, the marginal effect of the model result showed that the likelihood of choosing farm with off-farm activities as a livelihood strategy is decrease by $2.4 \%$ as a household gets access to use fertilizer in his farm. This study goes along with the finding by Woinishet [33] and Emmanuel [34].

Improved seed (IMSEED): like in fertilizer case, use of improved seed was found negatively and significantly affected the households' livelihood diversification into offfarming activities at less than $10 \%$ probability level. This result indicates that, households using improved seed are less likely diversify livelihood into off-farming activities than those who did not use. This may be due to the important role of improved seed in enhancing production and productivity of the crops. Those farmers who use of improved seed may produce more from unit area than those who not use and this can help them to have more access to required amount of food and income. This situation may avoid farmers wandering in search of off-farm activities which derived by 'demand push' factors i.e. not for the sake of asset accumulation rather fulfilling basic needs of the family. Holding other things constant, the probability of households' decision to choose farming with off-farming is dropped by $3.8 \%$ as the farmers abstain from using improved seed. This study opposes the finding by Adugna [25] in that agricultural input use positively related to livelihood diversification.

Leadership (LEADER): this variable was found to be positive and significant influence on livelihood diversification into non-farm activities at less than 5\% probability level. This implies that those farmers who have participated in social leadership in local area are more likely to diversify livelihood into non-farm activities than 
those farmers who have no leadership role in their community. The possible reason may be farmers' participation in local leadership can help to have more access for information, share more experience with others in social environment, creating more social network with out side societies, get more access for formal as well as informal credits. With regard to credit access, local leaders are more trusted and accepted by formal and informal financial institutions. Access for the credit can help to adopt production enhancing technology, and this in turn help to generate more income. Sometimes, credit helps them to invest directly in non-farming activities. Further, the positive relationship shows better leaders' education which equips them with necessary knowledge to engage in nonfarming activities. The result indicates that, other factor kept constant, the marginal effect of the model result showed that the probability of choosing farming with nonfarming as a livelihood strategy is increased by $27.2 \%$ as a household gets access to involve in local leadership. This result is inline with the finding of Dilruba and Roy [26].

\section{Conclusion and Recommendation}

Agriculture is the dominant economic activity and the primary source of livelihoods for rural households in the study area. However, due to small farm size, uncontrolled population growth, recurrent drought, the agricultural production has been deteriorating over time, and has forced people to look for alternative employment option other than agriculture. A significant number of rural households engage in diverse livelihood strategies away from purely crop and livestock production towards non-farm and offfarm activities that are undertaken to broaden and generate additional income for survival and livelihood improvement. From the finding of the research, it is increasingly becoming clear that the agricultural sector alone cannot be relied upon as the core activity for rural households as a means of improving livelihood, achieving food security and reducing poverty in the study area. Livelihood diversification is gaining/playing prominent role in rural households' income and food security. Even though, regarding the rural economy in Ethiopia, policy makers give almost full attention to agricultural sector. Nevertheless, there is a growing evidence that rural sector is much more than just farming.

The result of this study indicated that low resources endowments was main characteristics of poor wealth groups and this meager resource could not enable them to generate sufficient livelihood outcome. To overcome the situation, majority of poor households depend on other livelihood options rather than agriculture, which is not worthy. Further, the survey result also reveals this fact that rural households in the study area practice diversified livelihood strategies in addition to agriculture. The multinomial logistic (MNL) regression model was applied to answer the questions why rural households pursue diverse livelihood strategies. Results suggest that different livelihood strategies are influenced by different factors. The model result indicated that out of the 19 hypothesized variables in the model, 11 were found to be significantly influenced household's adoption of alternative livelihood strategies at $1 \%, 5 \%$ and $10 \%$ probability levels. These variables include agro-ecology, sex, education, farm size, livestock ownership, participation in social leadership, annual cash income, fertilizer use, improved seed use, age, and training. Accordingly, the model result indicated that the age of household head, agro-ecology and participation in local leadership influenced positively and significantly the choice of farming + non-farming, while the ownership of livestock in TLU and total farm size negatively and significantly affected the diversification of livelihood into non-farm, off-farm and combining non-farm and off-farm activities. Further, the variable education had positively and significantly influenced the household choices of farm + non-farm, farm + off-farm and farm + non-farm \& off-farm activities, whereas total annual cash income was found to have positive and significant influence of livelihood diversification into non-farm and combination of non-farm and off-farm activities. Similarly, use of fertilizer and improved seed had negative and significant influence on the household decision of selecting diversified livelihood strategies into farm + off-farm activities, while agricultural training had negative and significant influence on livelihood strategies choice of farm plus non-farm and offfarm activities.

Based on the findings of the study, the following policy recommendations are possible areas of intervention which might help to adopt best alternative livelihood strategies in the study area.

- The negative and significant influence of the variable sex on household livelihood strategies choice considers government and other responsible bodies to design necessary strategies so as to create awareness among the community to participate women equally with man in all development activities.

- The important roles of education and training in diversification of livelihood strategies suggests to give due attention in promoting farmers' education through strengthening and establishing both formal and informal type of education, developing farmers' training centers, expanding technical and vocational schools.

- The significant and positive effect of age on adoption of non-farm activities calls policies instruments to build capacity of rural farm households in the area of non-farm activities in order to enhance their skill to exploit the opportunity sustainably.

- The significant role of livestock ownership in livelihood security suggests to design development strategy for livestock sector through improving livestock breeds, veterinary services, forage development, marketing, access to credit and over all management of livestock production that aimed at improving rural household welfare in general and food 
security status in particular.

- The negative and significant impact of farm size on livelihood diversification suggests concerned bodies to develop appropriate strategies and policies especially for land resource-poor farmers. It also concerns promoting and creating positive environment for the emerging livelihood alternatives like non-farm activities. The presence of very small size of land calls for giving emphasis in agricultural intensification to enhance the productivity of the land so that generate adequate income and food.

- The agro-ecological influence on diversifying livelihood strategies has great implication for government to design context specific intervention and technologies which can improve the livelihood of rural household.

- The strong positive association of total annual cash income on livelihood strategies of the household calls for policy measures to pave the way in order to solve financial problems through developing and strengthening financial institution, creating credit access and promoting better income generating options.

- The strong negative association of chemical fertilizer and improved seed use with the diversification of livelihood strategies into farm + off-farm activities considers promoting timely supply of chemical fertilizer and improved seed coupled with appropriate credit and extension services.

- The positive and significant influence of households' local organization leadership participation on the choice of livelihood strategies points the direction to create access to information and other necessary services like credit for people in the same community. This also considers government and other responsible bodies in building capacity through education and training so as to participate actively in social activities and leadership.

\section{Acknowledgment}

The authors convey deepest thanks to Minster of Education for providing financial support for this research.

\section{References}

[1] MoA, 2010. Ethiopia Animal Health Year Book. Addis Ababa: Federal Ministry of Agriculture Animal and Plant Health Regulatory Directorate (APHRD).

[2] UNDP, 2011. Human development report. Sustainability and Equity: a better future for all.

[3] BTI, Bertelsmann Stiftung. 2012. Ethiopia Country Report. Gütersloh: Bertelsmann Stiftung.

[4] EEA, 2008. Report on the Ethiopian Economy, No. Volume VI 2006/07. Addis Ababa. Ethiopian Economic Association.
[5] FDRE, 2010. Ethiopia's agricultural sector policy and investment framework 2010-2020. Federal Democratic Republic of Ethiopia, Ministry of Agriculture and Rural Development. Draft final report, 15 September 2010

[6] FAO, 2012. World Food and Agriculture. Statistical Year Book. Rome, 2012

[7] FAO (Food and Agricultural Organization of the United Nations), 2010. The state of food insecurity in the world, Rome, 2010.

[8] Stifel, D. 2010. The Rural Non-farm Economy, Livelihood Strategies and Household Welfare African Journal of Agricultural and Resource Economics, 4(1).

[9] Reardon, T. 1997. Using evidence of household income diversification to inform the study of rural non-agricultural labor market in Africa, World Development, 25 (5):735-748.

[10] Barrett, C. B., Reardon, T. and Webb, P. 2001. Non-farm income diversification and household livelihood strategies in Rural Africa: Concepts, Dynamics, and Policy Implications" Food Policy, 26 (4): 315 - 31.

[11] Haggblade, S., Hazell, P. and Reardon, T., 2005. 'The Rural Nonfarm Economy: Pathway out of Poverty or Pathway http://www.ifpri.org/events/seminars/2005/smallfarms/sfpro c/S04_haggblade.pdf

[12] World Bank, 2009. Diversifying the rural economy: An assessment of the investment climate for small and informal enterprises in Ethiopia," October 6, 2009.

[13] Bush, J. 2002. Baseline household food economy assessment: Boloso Sore Woreda, Wolayita zone, Christinan Aid, Addis Ababa, Ethiopia

[14] WZFEDD, 2012. Wolaita Zone Socio-Economic information. Wolaita Zone Finance and Economic Development Department, May 2012.

[15] Dessalegn Rahmato, 2007. Development Intervention in Wollaita, 1960s-2000s: A Critical Review. FSS Monograph No. 4. Forum for Social Studies, Addis Ababa.

[16] CSA, 2010. Population and housing census of Ethiopia, A.A. http://www.csa.org. July 2010

[17] Greene, W. 2000. Econometric analysis. Englewood Cliffs, NJ: Prentice Hall.

[18] Chilot Yirga, 2007. The daynamics of soil degradation and incentives for optimal management in Central Highlands of Ethiopia. PhD. Dissertation, University of Pretoria.

[19] Keane, M.P. 1992. A Note on Identification in the Multinomial Probit Model. Journal of Business and Economic Statistics, Vol. 10, pp. 193-200.

[20] Chan, Y. H .2005. Basic statistics for doctors, multinomial logistic regression, Singapore

[21] Ghosh, J. and Bharadwaj, K., 1992, 'Poverty and Employment in India', in H. Bernstein, B. Crow and H. Johnson (eds) Rural Livelihoods: Crises and Responses, Oxford: Oxford University Press and The Open University.

[22] Berry, S., 1989a, Coping with Confusion: African Farmers' Responses to Economic Instability in the 1970s and 1980s, Boston: African Studies Centre, Boston University. 
[23] Bob Rijkers, 200. Rural non-farm enterprises in Ethiopia: challenges and prospects understanding the constraints to continued rapid growth in Ethiopia: the role of agriculture Africa Region, World bank, November 2008.

[24] Ellis, F. 2004. Occupational diversification in developing countries and implications for agricultural policy. December 2004, Hot Topic Paper.

[25] Adugna Eneyew Bekele, 2008. Livelihood strategies and food security in Wolaita, Southern Ethiopia: The case of Boloso Sore District. M.Sc.Thesis, October, 2008. Haramaya University

[26] Dilruba Khatun and B.C. Roy, 2012. Rural livelihood diversification in West Bengal: Determinants and Constraints. Agricultural Economics Research Review Vol. 25(No.1) January-June 2012 pp 115-124

[27] Dercon, S. and Krishnan, P. 1996. Income portfolios in rural Ethiopia and Tanzania: choices and constraints', Journal of Development Studies, 32(6): 850-875.

[28] Tesfaye Lemma, 2003. Livelihood strategies in the context of population pressure: A Case study in the Hararghe Highlands, Eastern Ethiopia. PhD Dissertation. University of Pretoria, South Africa.
[29] Mujib Urrehman, Jehanzeb and Mubina F. Rana, 2008. Five livelihood Strategies of different categories of households in rural areas of Abbottabad, Pakistan. Sarhad J. Agric. Vol.24, No.4, 2008

[30] Babatunde, R.O.; Olagunju, F.I.; Fakayode, S.B. and Adejobi, A.O. 2010. Determinants of participation in offfarm employment among small-holder farming households in Kwara State, Nigeria.

[31] Gebrehiwot Weldegebrial Gebru1 and Fekadu Beyene, 2012 Rural household livelihood strategies in drought-prone areas: A case of Gulomekeda District, eastern zone of Tigray, Ethiopia. Journal of Development and Agricultural Economics Vol. 4(6), pp.158-168, 26

[32] Isaac, B. 2009. Poverty and income diversification among households in rural Nigeria: A Gender Analysis of Livelihood Patterns. Oluwatayo Conference Paper No 41.

[33] Woinishet Asnake Sisay, 2010, Participation into off-farm activities in rural Ethiopia: who earns more? The Hague, The Netherlands November, 2010

[34] Emmanuel Ekow Asmah, (n.d). Rural livelihood diversification and agricultural sector reforms in Ghana. Research Fellow, Brookings (Africa Growth Initiative). EAsmah@brookings.edu 